\title{
LAS ORGANIZACIONES NO GUBERNAMENTALES PARA EL DESARROLLO (ONGD) EN ESPAÑA*
}

\section{CARMEN MARCUELLO SERVÓS Universidad de Zaragoza}

\section{PALABRAS CLAVE ADICIONALES}

Nuevos Movimientos Sociales, Economía

Social, Cooperación al Desarrollo.

\section{CHAIME MARCUELLO SERVÓS}

Universidad de Zaragoza

\author{
ADDITIONAL KEYWORDS \\ New Social Movement, Social Economy, \\ Cooperation for Development.
}

RESUMEN. En este artículo se analizan las Organizaciones No Gubernamentales para el DesarroIlo (ONGD) españolas, federadas en el marco de la Coordinadora de ONGD-España (CONGD-E). Estas organizaciones representan un conjunto consolidado dentro del sector más amplio de las Organizaciones No Lucrativas. Han pasado de la invisibilidad social, a la presencia creciente en los medios de comunicación y en el imaginario de la sociedad. Se han consolidado como actores sociales y como actores políticos. De hecho, desde un punto de vista sociológico son consideradas como una parte fundamental de los llamados nuevos movimientos sociales. Asimismo, también son agentes económicos que han pasado de la gestión de poco más de unas decenas de millones de pesetas a comienzos de los años ochenta, a unos ingresos de 40.000 millones en el año 1996. Junto a esto hay que destacar también la transformación estructural que han experimentado: incremento de personal contratado, de voluntariado, de oferta de servicios, de presencia internacional.

\footnotetext{
* Los datos utilizados para este estudio se han obtenido de la Coordinadora de ONGD-E para el periodo 1991-1996. Posteriormente a la elaboración del trabajo ha sido publicado el Directorio de ONGD 2000 por la citada Coordinadora. Los autores desean agradecer la colaboración de la Coordinadora de ONGD-E. Los puntos de vista expresados en este artículo corresponden a los autores y no representan las opiniones de dicha Coordinadora.
}

Revista Internacional de Sociología (RIS)

Tercera Época, nº 25, Enero-Abril, 2000, pp. 99-119. 


\section{INTRODUCCIÓN}

Las siglas ONG con las que se nombra habitualmente a las Organizaciones No Gubernamentales son confusas y poco claras' ${ }^{1}$. De hecho, con esa denominación se dice muy poco de lo que hacen, viven y son estas organizaciones. Por eso mismo, ha dado pie a numerosas controversias ${ }^{2}$, las cuales se han incrementado a medida que las ONG se han consolidado como referencia social y como agentes económicos. Hoy cualquier asociación, colectivo, comité o grupo ciudadano reclama para sí el uso de estas siglas. Lo «no-gubernamental» parece haber ganado $^{3}$ un espacio de prestigio - también de suspicacia - en la sociedad. Y si nos centramos en las ONG para el Desarrollo (ONGD), podemos decir que han pasado de la invisibilidad social ${ }^{4}$, a la presencia creciente en los medios de comunicación y en el imaginario de la sociedad. Se han consolidado como actores sociales y como actores políticos. De hecho, desde un punto de vista sociológico son consideradas como una parte destacada de los llamados nuevos movimientos sociales (Fernández y Riechman, 1996) que están presentando campañas de presión política cada vez mejor articuladas y más incisivas.

Nos encontramos, por tanto, ante unas siglas que, a pesar de decir poco, se han llenado de contenidos, de experiencias y han pasado a ocupar una posición con más densidad, tanto en la vida cotidiana, como en la arena internacional. Fruto de sus actividades, entre otros, es la Ley 23/1988 de 7 de junio de Cooperación Internacional para el Desarrollo. Aquellas organizaciones -que a comienzos de siglo no pasaban de las doscientas en todo el planeta- han multipli-

\footnotetext{
' Se considera que la primera ocasión en la que se utilizaron estos términos en un documento internacional, es el artículo 71 de la Carta de las Naciones Unidas, aprobado el 26 de junio de 1945 en San Francisco cuando señala: «El Consejo Económico y Social podrá hacer arreglos adecuados para celebrar consultas con organizaciones no gubernamentales que se ocupen de asuntos de la competencia del Consejo». Los gobiernos signatarios de la Carta, constataban, en su momento, la presencia de unas organizaciones que ocupaban un puesto destacado en el campo de las relaciones internacionales, hasta entonces privativo de los Estados.

${ }^{2}$ Aquí basta con recordar una referencia de las más tajantes, respecto a la cuestión: «Aparte de la pobreza de toda definición negativa - no ser gubernamental afirma poca cosa, sobre todo si se reciben dineros públicos y se depende indirectamente de un ministerio- la expresión es, sencillamente, incorrecta. Cualquier empresa comercial, por ejemplo, es una ONG. También lo es la mafia, o eso es lo que uno creía», Giner (1995).

${ }^{3}$ En otros trabajos, Marcuello (1996b y 1996c), se ha abordado la cuestión de la conquista de identidad en las ONGD y la génesis de esa denominación, en negativo.

${ }^{4}$ Entendemos por invisibilidad social la falta de, o la escasa, presencia de estas organizaciones en el imaginario social, en los medios de comunicación y en la vida pública. La invisibilidad era patente en el estudio encargado por la Coordinadora de ONGD a comienzos de su andadura en el año 1986 a Rosa Aparicio.
} 
cado su número ${ }^{5}$ los países del Norte y en los del Sur. Son organizaciones que han crecido en su capacidad de movilización social y de presión política, en sus recursos financieros y humanos, así como en su experiencia en la creación de redes y relaciones internacionales alternativas ${ }^{6}$ a los gobiernos que las bautizaron. Son organizaciones que han consolidado un espacio de actividad económica complementario a los tradicionales dentro del llamado Tercer Sector.

Si nos aproximamos a estas organizaciones desde el caso español, las ONGD son «las organizaciones que han difundido las siglas y las que también han llevado el liderazgo para llenarlas de contenidos» ${ }^{7}$. Sin embargo, desde grupos ecologistas, pacifistas o de derechos humanos, se considera que esto no es así. Las siglas ONG no son patrimonio de ningún sector. A pesar de ello, las ONG que reciben inicialmente tal denominación desde las administraciones públi$\mathrm{cas}^{8}$ - como receptoras de fondos-y a partir de las cuales se difunde la expresión, son las ONG especializadas en temas de Desarrollo. En el caso español, la multiplicación del número se produce a mediados de los 80 y hoy asistimos al uso generalizado de sus siglas, de sus actividades y de sus campañas de sensibilización y marketing.

Nuestro trabajo es un peldaño más en el análisis que venimos realizando de este proceso recorrido por las ONGD españolas, en concreto las federadas en la CONGD-E, sabiendo que en los últimos tres años han experimentado un ejercicio de autodefinición paralelo al de las ONGD integradas en el Comité de la Unión Europea, que ha concluido en el Código de Conducta y en la Carta de las ONGD de la Unión Europea, y recordando que, según las cifras del anuario de 1997, las ONGD de la Coordinadora tuvieron un volumen de ingresos superior a los 40.000 millones de pesetas.

Así, tenemos como punto de partida tres cuestiones a las que queremos aproximar una respuesta. La primera es averiguar si en función de las diferencias de

\footnotetext{
${ }^{5}$ Como aparece reflejado en el Informe de la Commission on Global Governance(1995), p. 32. las cifras que ofrece la Union of International Organizations (1993) son de 176 a principios de siglo y 28900 en 1996. En este repertorio consideran aquellas que actúan en más de tres países sin hacer distinciones entre ecologistas, pacifistas, de desarrollo o incluso sindicatos...

${ }^{6}$ Como nos contaba en una entrevista personal Xavier Gorostiaga, economista, ex-rector de la UCA de Managua, y consultor del Foro Alternativo de ONG en la Cumbre Mundial sobre Desarrollo Social de Copenhague (1995), «las ONG han pasado a ocupar una posición relevante en el terreno internacional»; considerando la evolución de las Cumbres internacionales desde Río de Janeiro, los Foros Alternativos han conquistado una presencia activa que no existía.

${ }^{7}$ Así se manifestaba el representante de una ONGD en la Asamblea ordinaria de la Coordinadora española de ONGD de 1995, lo que posteriormente dio pié al proceso de elaboración del Código de Conducta de las ONGD.

${ }^{8}$ Ver registro de ONG de la Agencia Española para la Cooperación Internacional.
} 
tamaño que existen entre las ONGD se pueden observar diferencias en la utilización de sus recursos. La segunda es contrastar cómo afecta la forma jurídica - asociación o fundación- de las ONGD a las formas de gestión y actuación. La tercera es comparar las diferencias que se producen en función del sector de vinculación al que pertenecen las ONGD.

El método que utilizaremos combina dos aspectos. Por un lado, el aporte cualitativo de los discursos de las propias ONGD. Por otro, la revisión de los datos que las propias ONGD de la Coordinadora ofrecen en su Anuario de 1997. Para el primero, partimos del trabajo de investigación realizado desde hace cuatro años a propósito de estas organizaciones y sus actores. Para el segundo, nos centraremos en los datos del Anuario de 1997 y en concreto en la revisión de cuatro variables: a) ingresos, según sus fuentes; b) gastos, atendiendo a su aplicación; c) recursos humanos, según sus diversos tipos y organizaciones; d) tipo de organización, según su «edad», extensión, vinculaciones, número de socios... Desde ese punto de partida es posible apuntar algunas repuestas plausibles a las tres cuestiones planteadas.

\section{ANÁLISIS DE LA ESTRUCTURA DEL SECTOR DE LAS ONGD ESPAÑOLAS}

Las ONGD en España se han sumado a la trayectoria internacional de crecimiento, prestigio y multiplicación. Las circunstancias históricas hicieron que los ritmos en las ONGD españolas fuesen distintos al resto de los países occidentales. Los años del franquismo marcaron todo lo que afectaba a los movimientos y organizaciones sociales. Sólo después de la Transición y con la progresiva homologación con el entorno europeo se comienzan a definir los elementos que permiten la aparición y multiplicación de las ONGD. Un proceso de innovación y dinamismo social que sigue activado a finales de los 90 .

\section{Rasgos generales}

Una forma de ordenar el proceso sociogenético de las ONGD españolas es el trabajo de $\mathrm{M}^{\mathrm{a}}$ Luz Ortega (1994). Esta autora propone tres etapas" que alcanzan hasta la preparación de su trabajo, pero que no incluyen el punto de inflexión producido a mediados de los 90 . La presencia generalizada de las ONGD en la opinión pública estaba por llegar. Por eso, hay que sumar a su tipificación, la

\footnotetext{
"Primera, hasta 1985, caracterizada por la ausencia de directrices. Segunda, de 1985 a 1989, en la que se constituyen la mayoría de las organizaciones. Tercera, a partir de 1989, que postula como un camino hacia la estabilización.
} 
expansión, difusión y visibilidad social provocada por dos elementos. Primero, la presencia de las ONGD en los desastres humanitarios recientes, junto a la cobertura mediática de los mismos. Segundo, las movilizaciones y huelgas de hambre por el $0,7 \%$, de 1994 y de 1995 . Estas acciones radicales y cargadas de tono apologético supusieron un aldabonazo en la sociedad española (Marcuello, 1996a) que colateralmente despertaron ${ }^{10}$ la relevancia del trabajo de las ONGD en contraste con las ayudas oficiales.

Antes de la década de los 80, podemos hablar de una proto-cooperación al desarrollo, tanto gubernamental, como no gubernamental, destacando de ésta el papel de las organizaciones vinculadas a la Iglesia ${ }^{11}$. Con la Transición Democrática en 1977 y la llegada del PSOE al gobierno, en 1982, se produjo un cambio cualitativo en los modos de asociación y participación en las materias de desarrollo desde esas organizaciones que ya se comenzaban a denominar como ONG. En este segundo momento, es muy importante la constitución de la Coordinadora $^{12}$ de ONGD como federación de asociaciones sin ánimo de lucro para la cooperación al desarrollo. Entonces las ONGD eran prácticamente invisibles $^{13}$ a la mirada colectiva de la sociedad española. Los medios de comunicación apenas habían reparado en su presencia. El punto de inflexión de los 90 marca la diferencia. La invisibilidad se ha tornado en prestigio social ${ }^{14}$. La fase de estabilización que postulaba Ortega (1994) ha derivado en algo distinto. Ha sido un paso adelante en el prestigio social. No se puede decir cuánto durará este fenómeno, pero las ONGD españolas han pasado a ocupar un lugar social en el imaginario colectivo español. Esto ha supuesto un cambio cualitativo en la ima-

\footnotetext{
${ }^{10}$ En la I Jornada de la Solidaridad de Zaragoza, organizada por la Plataforma 0,7\% en septiembre de 1996, uno de los carteles divulgativos recogía en seis puntos los llamados Logros del 0,7. Eran los siguientes: - Mayor conocimiento de las injusticias mundiales y del destino real de la ayuda oficial. - Triplicación de la ayuda descentralizada. - Incorporación a las ONG de Desarrollo de un mayor número de voluntarios. - Triplicación de la contribución de Administración central a los proyectos de las ONG. - Mayor concienciación social. - Aumento de las aportaciones de ciudadanos, asociaciones y empresas a la cooperación con el Sur.

"Algunos dicen que eso sólo eran actividades misioneras y proselitistas que no se deben entender como cooperación al desarrollo.

${ }^{12}$ Aunque no se registra oficialmente hasta diciembre de 1986, llevaba unos años ejerciendo como foro de coordinación entre las ONG que, a medida que las siglas cobraron prestigio, había añadido una $\mathrm{D}$ de desarrollo con la cual distinguirse de otros colectivos que también las utilizaban.

${ }^{13}$ Aunque no lo formula de este modo, se debe consultar el trabajo de Rosa Aparicio (1985).

${ }^{14}$ Primero, la publicidad gratuita dentro de la prensa. Segundo, la cooptación del lenguaje y de los éxitos por parte de los políticos. Tercero, la creciente presencia como sponsor de sus campañas por empresas privadas y públicas. Son tres espacios conquistados, no por arte de magia, ni por altruismo de los periódicos, los políticos y las empresas: si no tuviera "prestigio social» nadie estaría apoyando un concierto pro-Ruanda, por ejemplo (Marcuello, 1996b).
} 
gen de las ONGD, de la exigencia social hacia ellas y del prestigio de las propias siglas. Por eso creemos que, lejos de estabilizarse, las ONGD han entrado en una época de expansión mayor, dando lugar, en primer lugar, a la necesidad de consensuar su propia definición colectiva ante la sociedad, y en segundo lugar, a la independencia financiera y el ejercicio de la presión política.

Los datos cuantitativos del anuario de la CONGD-E de 1997 nos permiten contrastar los datos cualitativos registrados en nuestra investigación empírica. En la tabla 1 atendemos a tres aspectos: $1^{\circ}$ ) el tamaño de las ONGD en función de los fondos que ingresan; $2^{\circ}$ ) la forma jurídica que han elegido para legalizarse y $3^{\circ}$ ) dado el peso específico de las organizaciones de la Iglesia, la confesionalidad o no de las ONGD. En la tabla hemos considerado también la edad de las organizaciones, sus delegaciones en España y en el extranjero, así como el número de socios.

Las tablas que presentamos están elaboradas a partir de la información que las propias ONGD de la Coordinadora facilitan. Por eso mismo, es importante destacar que estas cifras reflejan la parte más relevante y destacada del sector español de ONGD, pero no lo abarcan en su totalidad. Si bien es cierto que la CONGD-E aglutina a las más importantes, no están todas las que son. Faltan aquellas pequeñas organizaciones surgidas más recientemente o que a pesar de llevar años desempeñando tareas de desarrollo han optado por no federarse.

Tabla 1.

Rasgos generales ONGD, 1996.

\begin{tabular}{|c|c|c|c|c|c|}
\hline & Número & Edad & $\begin{array}{c}\text { Delegaciones } \\
\text { España }\end{array}$ & $\begin{array}{c}\text { Delegaciones } \\
\text { Extranjero }\end{array}$ & $\mathrm{N}^{\circ}$ de socios \\
\hline \multicolumn{6}{|l|}{ Tamaño (Ingresos) } \\
\hline Ing. $<50$ Mill. & 24 & 10,75 & 6,69 & 3,83 & $1.974,57$ \\
\hline 50 Mill.<Ing. $<200$ Mill. & 31 & 10,16 & 6,96 & 4,08 & 782,93 \\
\hline Ing.>200 Mill. & 36 & 18,17 & 14,22 & 6,84 & $33.710,03$ \\
\hline \multicolumn{6}{|l|}{ Forma jurídica } \\
\hline Fundación & 62 & 17,55 & 11,42 & 7,14 & $5.749,33$ \\
\hline Asociación & 29 & 11,58 & 9,38 & 4,43 & $13.587,56$ \\
\hline \multicolumn{6}{|l|}{ Vinculación social } \\
\hline No confesional & 75 & 12,23 & 8,39 & 5,52 & $14.674,66$ \\
\hline Confesional & 16 & 19,38 & 16,53 & 5,17 & $8.763,56$ \\
\hline Media & 91 & 13,48 & 10,04 & 5,46 & $13.587,56$ \\
\hline Mediana & & 10,00 & 7,00 & 4,00 & 450,00 \\
\hline
\end{tabular}

Fuente: Directorio ONGD 1994, Directorio ONGD 1997 y elaboración propia. 
La edad de las ONGD españolas hace que exista un grupo consolidado en el que se ha cumplido la primera década de existencia. Las situaciones particulares dentro de la CONGD son variadas y diversas. Un núcleo numeroso de la Coordinadora lleva más de diez años funcionando. Tienen tras de sí un recorrido contrastado como organizaciones de la sociedad civil. Cada una con sus etapas y procesos propios, se han fraguado una serie de inercias y se pueden elaborar balances de las tareas realizadas.

En la tabla 1, también se corrobora la mayor $e d a d$ de las organizaciones vinculadas al sector confesional, lo cual puede dar pie a interpretaciones equívocas. Habitualmente se considera que una organización con más experiencia tiene un plus de calidad respecto a aquéllas que carecen de ese recorrido temporal. En este caso - como en tantos otros-, la «experiencia/edad» no tiene por qué ser un grado. De hecho, encontramos en los datos de nuestra investigación cualitativa - a partir de los discursos de las ONGD y sus personas- casos anclados en sistemas de cooperación al desarrollo previos a categorizaciones cruciales, como la sostenibilidad, la participación, el desarrollo endógeno... Existen ONGD que han transformado sus planteamientos puramente misionales en verdaderas organizaciones de desarrollo, pero también perduran aquellas instituciones religiosas que siguen con pautas preconciliares. La edad tomada una a una no es un dato relevante. Este aspecto tiene su verdadera densidad al ponderar el conjunto de las ONGD españolas. Y en eso observamos cómo se supera la década en la mayoría. Esto hay que correlacionarlo con: a) la evolución de la sociedad española; b) las transformaciones de los movimientos sociales y c) las transformaciones de la arena internacional, incluidas las propuestas de desarrollo humano del PNUD. La consolidación de este tejido de la cooperación al desarrollo desde la sociedad civil española es un paso más en la homologación con el entorno europeo y también muestra de una mímesis respecto a las pautas sociales de los socios de la Unión Europea. Todo ello camina en paralelo al uso que se ha hecho de la cooperación oficial por parte de los Estados, como mecanismo de diplomạcia y política exterior.

Dentro de los llamados «nuevos movimientos sociales», las ONGD españolas se han convertido en agentes dinamizadores que han prestigiado unas siglas y han pasado, como decíamos antes, a ocupar un lugar de referencia social. Lo cual también ha ido fraguando una red de delegaciones de ONGD. Es cierto que las delegaciones nos hablan de infraestructura, de servicios, de recursos disponibles. En este asunto la aportación cualitativa corrige la valoración optimista de este crecimiento cuantitativo. Las ONGD más grandes tienden a crear verdaderas redes de comercialización de su producto. A mayor tamaño en el volumen de ingresos, más red de delegaciones. Para las ONGD alejadas de los planteamientos empresariales, estas estrategias producen cierto rechazo. Es decir, aflora el debate de la incardinación/presencia social. Desde sus propios discursos - al plantear el autoanálisis de la inserción de las ONGD en la sociedad-, unas 
responden mostrando su red de tiendas, de sedes, de puntos en distintas partes de la geografía... mientras que otras consideran que esas ramificaciones no pasan de ser meras delegaciones comerciales donde lo único que se pretende es captar fondos. Esta última visión no se ajusta al espíritu de esa redificación. Las delegaciones en España presentan la expansión de las grandes organizaciones. Algunas de ellas, consustancialmente a su tejido organizativo, están en todas partes. Por ejemplo, Manos Unidas, Cruz Roja y Cáritas, tienen una génesis organizativa que las ha hecho así. Otras ONGD mucho más pequeñas ${ }^{15}$, pero sobre todo por decisión propia, han optado por quedarse en su territorio, como por ejemplo Acción Solidaria Aragonesa.

En la valoración de las delegaciones en España se tiene que considerar las afinidades ideológicas de las ONGD. La mayor parte de las grandes ONGD tienden a funcionar como verdaderas máquinas monopolizadoras que entran a copar el sector. Otras respetan los territorios consolidados y se retiran o ni siquiera llegan a introducirse. En ello se aprecian dos criterios diferenciados: la expansibilidad como necesidad y la autolimitación. Llamamos expansibilidad a la tendencia de las ONGD a crecer sin límites. Supuestamente comienzan por la llamada de un grupo local o por la fusión con otra organización -el caso paradigmático es Intermón. Su idiosincrasia es expansiva y no tienen más límites que su propia misión: «erradicar la pobreza del mundo». Para ese fin todos los brazos, recursos disponibles... y delegaciones en España son necesarios, mientras que otras siguen optando por no pasar de su tejido básico establecido ${ }^{16}$. Ambas estrategias tienen elementos positivos y tendencias perversas. La primera es monopolista. La segunda parece condenarse a la pequeñez y no avanzar. En ambos casos, la práctica muestra que son más las inercias positivas, que las posibles patologías. Y de hecho, las propias ONGD siguen planteándose como reto arraigar mucho más su actividad en pos de la solidaridad, desde la población. Aquéllas que recurran al sistema de tiendas/sede local, necesitan crear delegaciones, lo cual podría hacernos pensar en la posibilidad de planteamientos descentralizadores en las organizaciones. Pero la realidad es otra; las estructuras organizativas existentes tienden a mostrar pautas muy centralizadas, con esquemas de funcionamiento jerarquizado en los que las decisiones tienen un tránsito vertical muy definido. En las que más han crecido, los planteamientos asamblearios han pasado al recuerdo de los inicios. Algunos de sus responsables actuales tienen un discurso personal y elaborado para racionalizar la pérdida de ese mecanismo de participación asociativa. Las estructuras de estas grandes organizaciones tienden

\footnotetext{
${ }^{15}$ Ver los datos publicados por la Coordinadora de ONGD-E, Directorio ONGD 1997.

${ }^{16}$ Es decir, las estructuras organizativas, número de socios, capacidad de gestión de proyectos con los que comenzaron y se mantiene desde la crisis sin grandes cambios y ampliaciones.
} 
a prescindir de esas asambleas que son la forma de funcionar más habitual en las pequeñas.

Ello nos permite considerar la columna de los socios. Son muchos, pero no todos los deseados, ni todos iguales. Cuando se utiliza la palabra socio nos encontramos con grandes divergencias. Algunos son simplemente cotizantes que pasan un número de cuenta y se olvidan de cualquier otra cosa. Otros no cotizan, ni figuran, pero trabajan como voluntarios asociados a las actividades de la ONGD. En esto, se tiende a argüir que el peso de una ONGD es directamente proporcional al número de socios con el que cuenta. Y como dato numérico es importante, pero se debe introducir un factor de corrección: el poder de participación de las personas asociadas. Las ONGD grandes tienden a conceder poco margen de participación a sus «socios» en la toma de decisiones o en la gestión de la ONGD. Algunos argumentan que, por definición, esto no puede ser. Al mismo tiempo que otras personas entrevistadas de ONGD más pequeñas y menos impersonales argumentan formulando una pregunta: «¿cómo es posible ser socio y participar en una ONGD si ésta es una fundación con un patronato que toma las decisiones?». La cuestión es polémica. En algunos casos, da lugar a tensiones y en otros se responde negando la premisa. Mientras que unas, por su propia constitución, no saben cómo llegar a los movimientos sociales de base, otras son pura base social. Lo cierto es que todas las ONGD de la Coordinadora se plantean como reto conseguir una mayor inserción en la sociedad y un incremento de sus socios. De hecho, ese «capital humano» es una de las claves del futuro de las ONGD españolas; se podrá cuestionar la validez de la asociación que sólo quiere miembros que cotizan una vez al año; se podrá criticar a aquellas ONGD que recurren a la captación fácil de cotizantes sin preocuparse de transformar la situación en nuestra sociedad...; se podrán hacer más críticas en este sentido, pero el peso de esa bolsa de asociados es crucial para el ejercicio de las tareas de presión política que quieren hacer las ONGD de la Coordinadora.

\section{Estructura de ingresos}

Otro debate que se extiende a la sociedad, surge cuando se valoran los ingresos de las ONGD. El momento más polémico del año es el periodo posterior a las asignaciones de los fondos públicos destinados a la cooperación no-oficial. Tanto en la convocatoria estatal del IRPF, como en la de la SECIPI, o en los fondos de cooperación descentralizada, los análisis y balances que se hacen tienden a despertar todo tipo de suspicacias. De hecho, la propia estructura de ingresos de las ONGD de la Coordinadora muestra la relación de dependencia que existe de los fondos públicos (Tabla 2). Pero también en esta tabla se disipan algunos tópicos. Curiosamente, las organizaciones vinculadas a la Iglesia muestran una menor dependencia de los fondos públicos (un $46,01 \%$ de ingresos públicos en las Confesionales, frente al $73,49 \%$ en las No confesionales). Y frente al tópico, 
las ONGD más pequeñas son las que muestran mayor independencia de la financiación pública (un 53,04\% de ingresos públicos frente al 78,85\% de las medianas y el $70,15 \%$ de las grandes). En este reparto de los ingresos, las ONGD pequeñas están en una situación de segundo plano. Con ello también se debe acentuar la falsedad de aquellas críticas que ven las nuevas organizaciones como mecanismos para la creación de autoempleo o la mera obtención de fondos públicos. Frente a quienes critican la proliferación excesiva de organizaciones - mushroomización del sector-como camino de debilitamiento y de fragmentación de los fondos a gestionar, la tabla de los ingresos nos muestra una mayor dinamización de éstos, desde la sociedad civil, una sociedad civil que es mucho más generosa que la imagen generalizada de ella, sin ser tampoco la panacea. Se tiende a considerar que todas las organizaciones no lucrativas tienen una financiación pública cercana al $80 \%$. Pero de nuevo, frente al tópico, en el caso de las ONGD nos encontramos con que la media es más baja: $70 \%$ financiación pública y $30 \%$ financiación privada, con tendencia a aumentar en ambos casos los valores absolutos.

Tabla 2.

Estructura de ingresos en miles de pesetas, ONGD 1996.

\begin{tabular}{|c|c|c|c|c|c|}
\hline & Total & $\begin{array}{l}\text { Ingresos } \\
\text { Privados }\end{array}$ & $\begin{array}{c}\text { Ingresos } \\
\text { Privados } \\
\%\end{array}$ & $\begin{array}{l}\text { Ingresos } \\
\text { Públicos }\end{array}$ & $\begin{array}{c}\text { Ingresos } \\
\text { Públicos } \\
\%\end{array}$ \\
\hline \multicolumn{6}{|l|}{ Tamaño (Ingresos) } \\
\hline Ing. $<50$ Mill. & $24.112,54$ & $9.338,16$ & 46,96 & $14.774,38$ & 53,04 \\
\hline 50 Mill.<Ing.<200 Mill. & $108.966,89$ & $23.111,86$ & 21,15 & $85.855,03$ & 78,85 \\
\hline Ing.>200 Mill. & $1.003 .844,5$ & $474.428,85$ & 29,85 & $559.415,61$ & 70,15 \\
\hline \multicolumn{6}{|l|}{ Forma jurídica } \\
\hline Fundación & $565.926,17$ & $213.814,88$ & 26,75 & $352.111,28$ & 73,25 \\
\hline Asociación & $399.406,71$ & $190.635,33$ & 33,57 & $208.771,38$ & 66,43 \\
\hline \multicolumn{6}{|l|}{ Vinculación social } \\
\hline No confesional & $400.665,69$ & $140.157,81$ & 26,51 & $260.377,95$ & 73,49 \\
\hline Confesional & $678.190,63$ & $462.050,63$ & 53,99 & $216.140,00$ & 46,01 \\
\hline Media & $452.475,35$ & $198.022,22$ & 31,40 & $254.451,13$ & 68,60 \\
\hline Mediana & $126.567,66$ & $24.783,66$ & 21,31 & $91.910,94$ & 78,69 \\
\hline
\end{tabular}

Fuente: Directorio ONGD 1994, Directorio ONGD 1997 y elaboración propia. 


\section{Estructura de gastos}

La Tabla 3 presenta desglosados los gastos que refleja el Anuario de las ONGD de la Coordinadora. Estos gastos se distribuyen en tres grandes apartados - proyectos, sensibilización, gestión-y un cuarto que funciona a modo de cajón de sastre. Como era de esperar, el gasto destinado a proyectos vertebra el mayor volumen (una media de un 70,27\% de los gastos totales). Las ONGD tienen un objetivo claro y compartido: dedicar esfuerzos a la cooperación con sus contrapartes del Sur, lo que se traduce en fondos directamente destinados a proyectos. En la vida cotidiana, esta orientación da lugar a que desde las organizaciones del Sur se llame a las ONGD del Norte, «financieras». Así las cosas, podemos decir que las ONGD son primordialmente organizaciones canalizadoras/ gestoras de recursos, pero también algo más. Ese «algo más» tiene que ver directamente con la actividad en la sociedad donante. Los gastos dedicados a sensibilización se plantean para llevar a cabo actividades que puedan cambiar la visión que se tiene de la cooperación internacional, de forma que arraigue una conciencia cada vez mayor de solidaridad entre las personas. La tarea educativa abarca un amplio espectro de acciones. Unas se realizan dentro del sistema educativo, otras dan lugar a campañas de sensibilización masiva de la sociedad. El reto en este gasto es modificar el Norte para que las relaciones con el Sur sean de otro modo; la expresión compartida por todas las ONGD tiene forma de slogan: unas relaciones más solidarias. Asunto sobre el cual existe consenso en el término, pero con diferencias de fondo en cuanto a sus contenidos.

Vista la tabla, hemos de señalar la diferencia porcentual que supone para las ONGD pequeñas la dedicación de recursos a las tareas de sensibilización (un $12,13 \%$ de los gastos totales). A pesar de que el valor absoluto es treinta veces menor respecto a las grandes, el porcentaje muestra que las ONGD pequeñas dedican tres veces más que sus homónimas a este capítulo, y esto se debe relacionar con la inserción en tareas de base de las más pequeñas. Habitualmente también existen excepciones- el menor tamaño está ligado a una integración habitual en redes ciudadanas y movimientos sociales de base.

Los gastos de administración y captación de fondos constituyen el asunto más crítico de la estructura de gasto de las ONGD (media de un 8,94\% de los gastos totales). Este aspecto siempre está en el punto de mira de quienes quieren levantar suspicacias respecto a la actividad de las ONGD. Las propias organizaciones son conscientes de esta susceptibilidad. De hecho, la mayoría de las ONGD prestan mucha atención al control del gasto interno y de gestión. Lejos de ser un tema dejado de lado, es un asunto que preocupa a las propias organizaciones. Cualquier exceso o corrupción pasaría a considerarse una muestra con la que reprochar al conjunto de las ONGD su labor. Por eso mismo, en el Código de Conducta de la CONGD-E se subraya la importancia de la transparencia en la gestión y la exigencia de auditorías públicas con las que aclarar cualquier posible duda. 
Tabla 3.

Esctructura de gastos en miles de pesetas, ONGD 1996.

\begin{tabular}{|c|c|c|c|c|c|c|c|c|c|}
\hline & \multicolumn{2}{|c|}{ Gastos en Proyectos } & \multicolumn{2}{|c|}{ Gastos en Educación } & \multicolumn{2}{|c|}{ Gastos en Administración } & \multicolumn{2}{|c|}{ Otros gastos } & \multirow{2}{*}{$\begin{array}{l}\text { Total } \\
\text { Gastos }\end{array}$} \\
\hline & Absoluto & Porcentaje & Absoluto & Porcentaje & Absoluto & Porcentaje & Absoluto & Porcentaje & \\
\hline \multicolumn{10}{|l|}{ Tamaño (Ingresos) } \\
\hline Ing.<50 Mill. & $16.837,49$ & 62,26 & $3.649,13$ & 21,40 & $2.062,96$ & 11,44 & 793,59 & 4,91 & $23.343,16$ \\
\hline 50 Mill. $<$ Ing. $<200$ & ill. $76.192,30$ & 73,19 & $11.431,56$ & 10,43 & $9.462,03$ & 8,36 & $9.372,40$ & 0,02 & $106.658,28$ \\
\hline Ing.>200 Mill. & $820.254,35$ & 73,10 & $87.277,33$ & 7,41 & $77.105,844$ & 7,76 & $58.544,81$ & 11,72 & $1.043,182,3$ \\
\hline \multicolumn{10}{|l|}{ Forma jurídica } \\
\hline Fundación & $454.170,91$ & 68,76 & $36.172,63$ & 9,74 & $43.383,81$ & 11,11 & $40.566,82$ & 109,40 & $574.294,2$ \\
\hline Asociación & $308.455,83$ & 70,98 & $40.886,05$ & 13,25 & $30.008,28$ & 7,92 & $20.112,35$ & 7,85 & $399.462,5$ \\
\hline \multicolumn{10}{|l|}{ Vinculación social } \\
\hline No confesional & $297.994,14$ & 70,18 & $40.102,14$ & 11,30 & $35.112,06$ & 9,43 & $30.690,20$ & 9,41 & $404.077,5$ \\
\hline Confesional & $608.030,13$ & 72,67 & $33.821,04$ & 16,04 & $28.522,83$ & 6,41 & $5.745,49$ & 6,06 & $676.119,5$ \\
\hline Media & $354.892,50$ & 70,27 & $39.383,97$ & 12,13 & $34.270,82$ & 8,94 & $26.630,81$ & 8,66 & $455.178,09$ \\
\hline Mediana & $80.819,19$ & 83,01 & $4.958,00$ & 4,42 & $6.238,04$ & 5,67 & 979,45 & 1,04 & $106.592,36$ \\
\hline
\end{tabular}

Fuente: Directorio ONGD 1994, Directorio ONGD 1997 y elaboración propia. 


\section{Estructura de personal}

Otro elemento crucial para estudiar las ONGD es su estructura de personal. Los datos de la Tabla 4 ofrecen unas cifras en las que se distingue el total del personal, considerando, por un lado, la presencia en sede - central o extensiones en España-y, por otro, los proyectos en el extranjero. Pero no se puede precisar el tipo de contrato y las diferencias que en la realidad existen en cuanto a esta cuestión. Sí que se diferencian, en un segundo momento, los voluntarios de los contratados. Aquí es importante destacar que el debate sobre el voluntariado no está cerrado dentro de las organizaciones. Para muchas personas contratadas por ONGD su trabajo remunerado es una forma de voluntariado, puesto que ni sus emolumentos, ni su dedicación, ni otros muchos aspectos de la gestión cotidiana, pueden compararse con un contrato de similares características en cualquier otra institución. Para otras, esto incluso es una exigencia con la que se ha de contar. En el extremo contrario están quienes consideran que ha de quedar muy claro las atribuciones y responsabilidades de quienes cobran y de quienes no lo hacen. En esta faceta de las ONGD españolas, los datos existentes nos permiten hablar de las correlaciones que muestran la polaridad voluntarios/contratados sin entrar en los detalles de fondo. A este respecto, sí que hay que destacar el incremento de personal como otro de los puntos que muestran el aumento de sus actividades. Y de nuevo aparece un elemento donde hay que destacar el papel por el que han optado las ONGD más pequeñas. Para ellas, los proyectos y sus actividades son más relevantes que la ampliación de su institución. En coherencia, tienen más personal destinado a los proyectos, que en las sedes (en valor absoluto, 172,75 personas, frente a 23,06 de las medianas y 130,5 de las grandes). Otra consideración que se debe plantear es la que se observa al atender al peso del voluntariado tanto en las ONGD del sector confesional, como en las asociaciones no confesionales. Aunque siempre se encuentran excepciones, se corrobora de nuevo la mayor implantación de las organizaciones de Iglesia en la sociedad española.

\section{ANÁLISIS DE LA EVOLUCIÓN DURANTE EL PERIODO 1992-1996}

Antes hemos dicho que la evolución de las ONGD - y de la cooperación al desarrollo, en general - ha pasado de la inexistencia a la consolidación y el prestigio creciente. La evolución registrada por el colectivo de ONGD de la Coordinadora - tomando como referencia los datos existentes - da fe de esta afirmación. Si atendemos a los aspectos señalados antes, podemos ver en qué se traduce esta consolidación.

En lo que afecta a la evolución de los ingresos desde 1991 hasta 1996 se observa un incremento constante de las aportaciones públicas, mientras que las 
Tabla 4.

Estructura de personal, ONGD 1996.

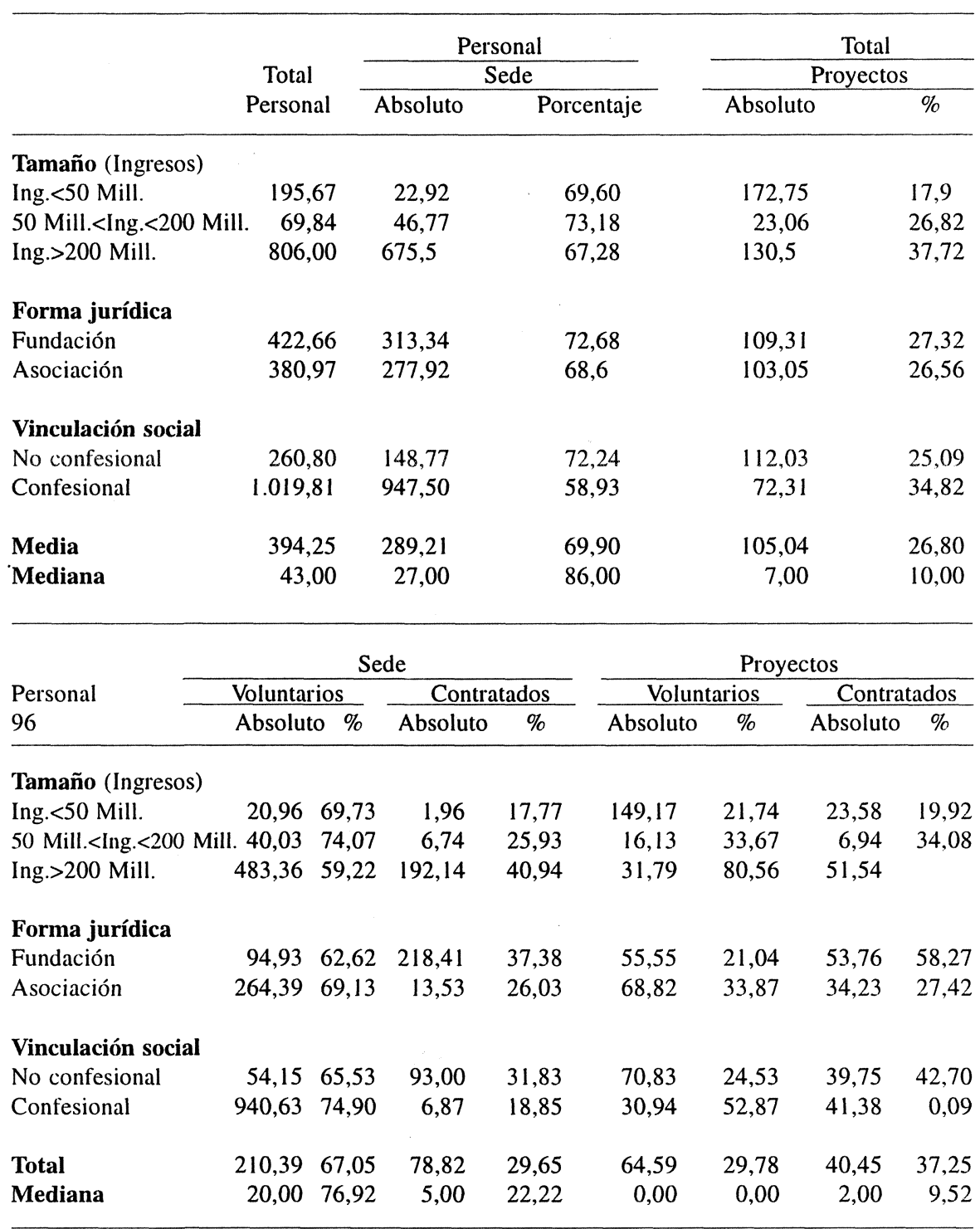

Fuente: Directorio ONGD 1994, Directorio ONGD 1997 y elaboración propia. 
Tabla 5.

Evolución ingresos (1991-1996)

\begin{tabular}{|c|c|c|c|c|c|c|c|c|c|c|c|c|}
\hline & \multicolumn{6}{|c|}{ Ingresos privados $(\%)$} & \multicolumn{6}{|c|}{ Ingresos públicos (\%) } \\
\hline & 1991 & 1992 & 1993 & 1994 & 1995 & 1996 & 1991 & 1992 & 1993 & 1994 & 1995 & 1996 \\
\hline \multicolumn{13}{|l|}{ Tamaño } \\
\hline Ingr.<50 Mill. & 51,15 & 53,25 & 51,67 & 61,88 & 51,89 & 46,96 & 48,85 & 16,75 & 48,33 & 43,00 & 48,11 & 53,04 \\
\hline 50 Mill. $<$ Ing. $<200$ & Mill. 40,92 & 43,54 & 35,05 & 38,37 & 27,35 & 21,15 & 59,08 & 6,46 & 60,86 & 61,63 & 72,65 & 78,85 \\
\hline Ing.>200 Mill. & 56,45 & 47,14 & 41,31 & 38,41 & 30,51 & 29,85 & 43,55 & 52,86 & 58,69 & 61,59 & 69,49 & 70,15 \\
\hline \multicolumn{13}{|l|}{ Forma jurídica } \\
\hline Fundación & 45,90 & 51,65 & 52,62 & 52,48 & 41,81 & 26,75 & 54,10 & 48,35 & 47,38 & 51,37 & 58,19 & 73,25 \\
\hline Asociación & 51,38 & 49,10 & 56,21 & 48,01 & 38,73 & 33,57 & 48,62 & 50,90 & 41,79 & 53,60 & 61,27 & 66,43 \\
\hline \multicolumn{13}{|l|}{ Vinculación social } \\
\hline No confesional & 37,02 & 36,08 & 28,92 & 42,16 & 33,95 & 26,51 & 62,98 & 63,92 & 71,08 & 60,73 & 66,05 & 73,49 \\
\hline Confesional & 65,31 & 65,90 & 59,26 & 75,37 & 60,32 & 53,99 & 34,69 & 34,10 & 37,41 & 24,06 & 39,68 & 46,01 \\
\hline \multicolumn{13}{|l|}{ Media } \\
\hline Absoluta & $130.108,4$ & $144.981,9$ & $171.002,2$ & $218.152,1$ & $163.085,7$ & $198.022,2$ & $65.234,3$ & $88.850,01$ & $124.424,9$ & $150.518,5$ & $206.316,9$ & $254.451,1$ \\
\hline Media \% & 49,83 & $3 \quad 49,68$ & 43,33 & 39,54 & 31,40 & 50,17 & 50,32 & 55,41 & 52,92 & 60,46 & 68,60 & \\
\hline
\end{tabular}

Fuente: Directorio ONGD 1994, Directorio ONGD 1997 y elaboración propia. 
aportaciones privadas tienen un cierto nivel de oscilación que discurre paralelamente a los desastres humanitarios. El punto de referencia es el año 1994. Los ingresos en conjunto se incrementan al considerar todo el período. En el caso de los ingresos públicos, es consecuencia directa de la aplicación de los criterios internacionales que recomiendan el $0,7 \%$ del PIB como referencia para la cooperación al desarrollo, cifras que deberán seguir creciendo hasta alcanzar los niveles de los países homólogos del entorno de la Unión Europea. A pesar de la llamada «fatiga de la ayuda», España todavía tiene mucho que crecer en esta materia.

Si atendemos a la evolución en función del tamaño de las ONGD, se observa un incremento de los ingresos públicos, especialmente en las medianas y grandes ONGD, frente a las pequeñas, que se mantienen relativamente estables en un equilibrio de ingresos públicos y privados. En esto influye la política pública de distribución de fondos a las ONGD consolidadas: se tiende a dar más a las que más tienen. Y esto también es consecuencia directa de la capacidad de gestión de las propias ONGD. Aquéllas que tienen un aparato administrativo más dotado y con más recursos son capaces de presentar y gestionar un mayor número de proyectos. La polaridad expansibilidad/autolimitación, señalada antes, es un modo de explicar lo que sucede: cuanto más grande se es, más se crece - salvo aquéllas cuyos estatutos ponen el tope de 50-50, como Intermón. En general, se sigue aceptando que cuanto más grande se es - en capacidad de gestión y fondosmás fuerte es la organización. Pero esto no es una correlación directamente proporcional con el prestigio y la implantación social.

Podemos atender a la distinción entre fundaciones y asociaciones. Establecemos como hipótesis que las primeras tienden a ser estructuralmente organizaciones con menor participación de sus socios frente a las asociaciones; lo cual, aunque no quiere ser un indicador de mejor gestión, sí que permite mayor agilidad en la gestión diaria, en comparación a las asociaciones donde las asambleas demoran la toma de decisiones. Ello también puede ser una explicación plausible a la vista de lo que se refleja en la evolución de los ingresos.

Por otra parte, si distinguimos entre las ONGD con vinculación a la Iglesia de las que no la tienen, observamos una mayor dependencia de los ingresos públicos en las segundas, esto asociado a un incremento en ambos casos, pero siempre por debajo del 50\% en el caso de las ONGD con ascendencia confesional. El peso de los ingresos privados es un elemento clave para que se produzca esta distribución.

Si pasamos a considerar la evolución de la estructura de gasto, se observa un incremento paulatino en el gasto dedicado a proyectos: se dedican más fondos a la realización de los proyectos. Sin embargo, las ONGD grandes y pequeñas han reducido el porcentaje dedicado a este output. Si miramos este ítem considerando el criterio de su estructura legal, vemos que las asociaciones no confesionales han aumentado el gasto en proyectos y lo mismo ocurre respecto a las confesionales, lo cual puede dar lugar a dos explicaciones. Por un lado, se puede 
Tabla 6.

Evolución de los gastos (1991-1996)

Gastos en proyectos (\%)

Otros gastos (\%)

\begin{tabular}{|c|c|c|c|c|c|c|c|c|c|c|c|c|}
\hline & 1991 & 1992 & 1993 & 1994 & 1995 & 1996 & 1991 & 1992 & 1993 & 1994 & 1995 & 1996 \\
\hline \multicolumn{13}{|l|}{ Tamaño } \\
\hline & 35,09 & 38,64 & 42,81 & 39,27 & 42,45 & 37,74 \\
\hline$<200$ Mill. & 64,13 & 78,54 & 76,77 & 64,07 & 63,16 & 73,19 & 35,87 & 21,46 & 23,33 & 35,93 & 36,84 & 26,81 \\
\hline Ing.>200 Mill. & 77,58 & 77,44 & 86,52 & 77,54 & 77,34 & 73,10 & 22,42 & 22,56 & 13,48 & 22,46 & 22,66 & 26,90 \\
\hline \multicolumn{13}{|l|}{ Forma jurídica } \\
\hline Fundación & 67,47 & 72,69 & 76,55 & 65,69 & 63,57 & 68,76 & 32,53 & 27,31 & 23,45 & 34,31 & 36,43 & 31,24 \\
\hline Asociación & 66,99 & 67,50 & 69,65 & 66,40 & 64,76 & 70,98 & 33,01 & 32,50 & 30,35 & 33,60 & 35,24 & 29,02 \\
\hline \multicolumn{13}{|c|}{ Vinculación social } \\
\hline No confesional & 169,96 & 67,86 & 71,33 & 64,15 & 62,36 & 70,18 & 30,04 & 32,14 & 28,67 & 35,85 & 37,64 & 29,82 \\
\hline Confesional & 63,70 & 69,67 & 71,04 & 73,57 & 71,86 & 72,67 & 36,30 & 30,33 & 28,96 & 26,43 & 28,14 & 27,33 \\
\hline \multicolumn{13}{|l|}{ Media } \\
\hline Media \% & 67,12 & 68,68 & 71,19 & 66,46 & 64,65 & 70,27 & 32,88 & 31,32 & 28,81 & 33,54 & 35,35 & 29,73 \\
\hline
\end{tabular}

Fuente: Directorio ONGD 1994, Directorio ONGD 1997 y elaboración propia. 
entender que en tanto en cuanto aumenta la realización de proyectos de cooperación, entonces la ONGD está cumpliendo con su deber. Por otro, aquéllas que no incrementan su actividad han caído en la cuenta de la importancia de una mayor sensibilización y mejora de la gestión interna. En cualquier caso, el criterio para calificar este gasto no es sólo el volumen final. Mayor número de proyectos con más fondos no quiere decir mejor cooperación ni mejor gestión. Las propias personas de las ONGD muestran en sus discursos las paradojas que se producen sobre el terreno, y la necesidad que existe de buscar métodos, indicadores y modos de evaluación de sus proyectos, más allá de las auditorías contables y de gestión.

Los datos respecto a la evolución del personal en las ONGD españolas muestran que el total de personas ligadas a las organizaciones se ha incrementado ligeramente. Sin embargo, también se observa una gran heterogeneidad y diversidad de movimientos. Al considerar los porcentajes se ve una mayor continuidad. En el trasfondo, la fluctuación del voluntariado va muy ligada a la presencia de las ONGD en la opinión pública y las campañas de solidaridad al respecto. También ha aumentado la necesidad gubernativa de buscar instituciones capaces de absorber a los objetores en su fase de prestación social sustitutoria. Estos

Tabla 7.

Evolución estructurada de personal total (voluntarios y contratados) 1993-1996

\begin{tabular}{|c|c|c|c|c|c|c|c|c|c|}
\hline & \multicolumn{3}{|c|}{ Total Personal } & \multicolumn{3}{|c|}{ Voluntarios } & \multicolumn{3}{|c|}{ Contratados } \\
\hline & 1993 & 1995 & 1996 & 1993 & 1995 & 1996 & 1993 & 1995 & 1996 \\
\hline \multicolumn{10}{|l|}{ Tamaño } \\
\hline $\begin{array}{l}\text { Ing.<50 Mill. } \\
50 \text { Mill.<Ing. }\end{array}$ & 164,68 & 120,68 & 195,67 & 70,55 & 82,76 & 68,24 & 29,45 & 17,24 & 19,26 \\
\hline <200 Mill. & 204,93 & 58,83 & 69,84 & 68,60 & 62,94 & 71,30 & 31,40 & 37,06 & 28,70 \\
\hline Ing.>200 Mill. & 505,02 & $2.404,36$ & 806,00 & 47,03 & 43,03 & 55,23 & 52,97 & 56,97 & 44,77 \\
\hline \multicolumn{10}{|c|}{ Forma jurídica } \\
\hline Fundación & 260,75 & $1.619,23$ & 422,66 & 39,66 & 56,62 & 60,34 & 43,24 & 43,38 & \\
\hline Asociación & 254,93 & 494,70 & 380,97 & 71,72 & 66,45 & 67,65 & 28,28 & 33,55 & 27,51 \\
\hline \multicolumn{10}{|l|}{$\begin{array}{l}\text { Vinculación } \\
\text { social }\end{array}$} \\
\hline No confesion. & 61,32 & 174,96 & 257,93 & 55,34 & 60,15 & 61,35 & 44,66 & 39,85 & 35,99 \\
\hline Confesional & 480,02 & $3.194,60$ & $1.019,81$ & 75,09 & 76,06 & 77,77 & 24,91 & 23,94 & 15,98 \\
\hline Media & 256,23 & 826,92 & 394,25 & 64,54 & 63,59 & 64,14 & 35,46 & 36,41 & 32,57 \\
\hline
\end{tabular}

Fuente: Directorio ONGD 1994, Directorio ONGD 1997 y elaboración propia. 
datos no están disponibles, pero sí que afectan a la estructura de personal en conjunto. Por otra parte, si antes se veía un aumento de proyectos y de fondos, esto debería discurrir en paralelo al incremento de personas que han de estar dedicadas a las tareas derivadas de la gestión de los proyectos y de las campañas de sensibilización, cuestión que no se refleja en los datos respecto a las personas implicadas.

En este aspecto, podemos proponer como explicación de los datos, la consolidación de las ONGD en tanto que organizaciones con unas estructuras internas, que ya saben cuáles son sus límites y cuáles son sus intereses. Sólo si las tomásemos de una en una podríamos detallar las claves de la heterogeneidad. Tras más de diez años de media de vida de las ONGD de la Coordinadora, las propias organizaciones muestran que en este aspecto están estabilizadas. Y esto no es producto de un estancamiento como ONGD, sino un elemento de consolidación, mientras que, si se ve con respecto al incremento del voluntariado, la interpretación es radicalmente distinta. Es uno de los retos que las propias ONGD formulan: el arraigo en la sociedad civil pasa por la implicación de mayor número de personas en las actividades de las organizaciones, y esto porque, muchas veces, las propias ONGD no saben cómo dar salida a las ofertas de las personas que se acercan.

\section{CONCLUSIONES}

El sector de las ONGD españolas vinculadas a la Coordinadora de ONGD-E nos ofrecen un espacio económico, social y político activo a la vez que consolidado. A pesar de que ninguna estructura o proceso social es irreversible, en este sector vemos una trayectoria ascendente que tiene por delante expectativas de crecimiento, ya que la cooperación al desarrollo parece que seguirá siendo una herramienta necesaria para paliar el llamado problema Norte-Sur. Las ONGD del Norte, cuya vocación interna es a desaparecer, lejos de ver ese futuro como algo cercano, parecen estar abocadas a una mayor presencia social e internacional.

En el caso de las ONGD españolas, se constatan dos deficiencias que afectarán directamente a la evolución posterior: a) su relativa dependencia de los fondos públicos y b) su escasa vinculación social. Las propias ONGD lo formulan así y trabajan en ello. Una propuesta que se plantea es la fusión de organizaciones o, cuando menos, la llamada a la no-proliferación de nuevas siglas, grupúsculos o nuevas ONG. Muchos responsables de las ONGD consolidadas ven en esto un requisito de supervivencia de la propia actividad de cooperación al desarrollo desde la sociedad civil. Sin embargo, otros plantean que lo que se hace es caer en mecanismos monopolistas. Para los segundos, la disminución de organizaciones en pos de unas pocas muy fuertes no es garantía de una mayor implantación social, que en definitiva es, para este grupo, el problema central. La polé- 
mica está sin resolver. Sólo podremos analizarla a medida que transcurra el tiempo. Mientras tanto, como estrategia operativa las ONGD tienden a crear foros de coordinación cada vez más localizados y presentes en las redes locales o autonómicas. El reto es hacer de la solidaridad una preocupación constante de la sociedad.

\section{BIBLIOGRAFÍA}

APARICIO, R. (1986), Estudio sobre conocimiento, imagen y actitudes de la ayuda al Tercer Mundo, para la CONGD. Mimeo Riddel, S.A.

CEONGD-UE and CONGD (1997), Carta de las ONGD. Principios básicos de las ONG de Desarollo y Ayuda Humanitaria en la Unión Europea, Madrid, Ed. CONGD.

CONGD (1996), Memoria de actividades Coodinadora de ONGD 1995. (mimeo).

(1997a), Memoria de actividades Coodinadora de ONGD 1996. (mimeo)

(1997b), Directorio de ONGD-E, Congd-Aeci, Madrid.

COMMISSION ON GLOBAL GOVERNANCE (1995), Our Global Neighbourhood, Oxford Press.

FERNÁNDEZ BUEY, J. y J. RIECHMAN (1996), Redes que dan libertad, Madrid, Paidós.

GINER, S. (1995), “Lo privado público: altruismo y politeya democrática”, Dcto. de trabajo 9506. IESA.CSIC, Madrid.

KORTEN, D. (1990), Getting to the 2lst century: Voluntary action and the global agenda, West Hartfort.

MAGADOUX, A.L. y D. ROCA (1989), Las ONG y la Cooperación para el Desarrollo. Documentos para el Desarrollo. Ed. Dpto. de Infor. Relaciones Públicas y Publicaciones de CRUZ ROJA ESPAÑOLA, Madrid.

MARCUELLO, Ch. (1996a), «El movimiento 0,7: un pulso colectivo», Acciones e Investigaciones Sociales, $\mathrm{n}^{\circ} 4$, abril, pp.201-218.

(1996b), «Identidad y acción de las Organizaciones No-Gubernamentales», Revista de Gestión Pública y Privada, $\mathrm{n}^{\circ} 1$, pp.103-122.

(1996c), «Las Organizaciones No-Gubernamentales de Desarrollo y la construcción positiva de su identidad», Acciones e Investigaciones Sociales, diciembre-96, n5. pp.103-119.

MARTÍNEZ SÁNCHEZ, J.L. (1998), La imagen de las ONG para el Desarrollo, Madrid, IEPALA.

ORTEGA, Mª L. (1994), Las Ongd y la crisis del desarrollo. Un análisis de la cooperación con Centroamérica, Madrid, IEPALA. 
SENILLOSA, I.(1996), «El papel de las ONG en el Norte», en Documentos de la Conferencia SurNorte, Juntos para la erradicación de la pobreza, Junio, 40 aniversario de Intermón, Barcelona.

UNION OF INTERNATIONAL ORGANIZATIONS (1993), Yearbook of International Organisations 1993-1994, Munich, KG, Sauverlag.

SUMMARY. We present a study of the Non-governmental Organisations for the Development (NGOD) Spanish, members of Coordinator of NGOD- Spain (CNGOD-AND). These organisations represent a set consolidated within sector wider of the Non-profit Organisations. They have gone from the social invisibility to the growing presence in the media and in the imaginary of the society. They have been consolidated as social actors and as political actors. In fact, from a sociological point of view they are considered as a fundamental part of the new social movements. Also, they are economic agents, since they manage tens of million of pesetas around the beginning of the eighties and 40 billion in the year 1996. We analyse also the structural transformation that they have experimented in the last five years: contracted personnel increase, number of volunteer, number of services offer and international presence.

E-mail: cmarcue@posta.unizar.es y chaime@ posta.unizar.es 